\title{
Right ventricular-arterial uncoupling independently predicts survival in COVID-19 ARDS
}

Michele D'Alto ${ }^{1 *+}$ (1), Alberto M. Marra ${ }^{2 \dagger}$, Sergio Severino ${ }^{3}$, Andrea Salzano $^{4}$, Emanuele Romeo ${ }^{1}$, Rosanna De Rosa ${ }^{5}$, Francesca Maria Stagnaro ${ }^{2}$, Gianpiero Pagnano ${ }^{3}$, Raffaele Verde ${ }^{3}$, Patrizia Murino ${ }^{5}$, Andrea Farro ${ }^{1}$, Giovanni Ciccarelli ${ }^{1}$, Maria Vargas ${ }^{6}$, Giuseppe Fiorentino ${ }^{7}$, Giuseppe Servillo ${ }^{6}$, Ivan Gentile ${ }^{8}$, Antonio Corcione ${ }^{5}$, Antonio Cittadini ${ }^{2}$, Robert Naeije ${ }^{9 \dagger}$ and Paolo Golino ${ }^{1+}$

\begin{abstract}
Aim: To investigate the prevalence and prognostic impact of right heart failure and right ventricular-arterial uncoupling in Corona Virus Infectious Disease 2019 (COVID-19) complicated by an Acute Respiratory Distress Syndrome (ARDS).

Methods: Ninety-four consecutive patients (mean age 64 years) admitted for acute respiratory failure on COVID-19 were enrolled. Coupling of right ventricular function to the pulmonary circulation was evaluated by a comprehensive trans-thoracic echocardiography with focus on the tricuspid annular plane systolic excursion (TAPSE) to systolic pulmonary artery pressure (PASP) ratio
\end{abstract}

Results: The majority of patients needed ventilatory support, which was noninvasive in 22 and invasive in 37 . There were 25 deaths, all in the invasively ventilated patients. Survivors were younger ( $62 \pm 13$ vs. $68 \pm 12$ years, $p=0.033$ ), less often overweight or usual smokers, had lower NT-proBNP and interleukin-6, and higher arterial partial pressure of oxygen $\left(\mathrm{PaO}_{2}\right)$ /fraction of inspired $\mathrm{O}_{2}\left(\mathrm{FIO}_{2}\right)$ ratio $(270 \pm 104 \mathrm{vs.} 117 \pm 57 \mathrm{mmHg}, p<0.001)$. In the non-survivors, PASP was increased ( $42 \pm 12$ vs. $30 \pm 7 \mathrm{mmHg}, p<0.001$ ), while TAPSE was decreased (19 $\pm 4 \mathrm{vs} .25 \pm 4 \mathrm{~mm}, p<0.001$ ). Accordingly, the TAPSE/PASP ratio was lower than in the survivors $(0.51 \pm 0.22 \mathrm{vs} .0 .89 \pm 0.29 \mathrm{~mm} / \mathrm{mmHg}, p<0.001)$. At univariate/multivariable analysis, the TAPSE/PASP (HR: 0.026; 95\% Cl 0.01-0.579; $p: 0.019)$ and $\mathrm{PaO}_{2} / \mathrm{FlO}_{2}(\mathrm{HR}: 0.988$; $95 \% \mathrm{Cl} 0.988-0.998 ; p: 0.018$ ) ratios were the only independent predictors of mortality, with ROC-determined cutoff values of $159 \mathrm{mmHg}$ and $0.635 \mathrm{~mm} / \mathrm{mmHg}$, respectively.

\footnotetext{
*Correspondence: mic.dalto@tin.it

${ }^{\dagger}$ Michele D'Alto and Alberto M. Marra take responsibility for all aspects

of the reliability and freedom from bias of the data presented and their discussed interpretation

${ }^{\dagger}$ Michele D'Alto and Alberto M. Marra have contributed equally to this manuscript.

${ }^{\dagger}$ Robert Naeije and Paolo Golino have contributed equally to this manuscript.

${ }^{1}$ Department of Cardiology, Monaldi Hospital - "L. Vanvitelli" University, Naples, Italy

Full list of author information is available at the end of the article
}

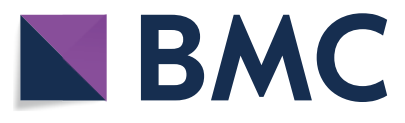

Aurs 2020. Open Access This article is licensed under a Creative Commons Attribution 4.0 International License, which permits use, sharing, adaptation, distribution and reproduction in any medium or format, as long as you give appropriate credit to the original author(s) and the source, provide a link to the Creative Commons licence, and indicate if changes were made. The images or other third party material in this article are included in the article's Creative Commons licence, unless indicated otherwise in a credit line to the material. If material is not included in the article's Creative Commons licence and your intended use is not permitted by statutory regulation or exceeds the permitted use, you will need to obtain permission directly from the copyright holder. To view a copy of this licence, visit http://creativecommons.org/licenses/by/4.0/. The Creative Commons Public Domain Dedication waiver (http://creativeco mmons.org/publicdomain/zero/1.0/) applies to the data made available in this article, unless otherwise stated in a credit line to the data. 
Conclusions: COVID-19 ARDS is associated with clinically relevant uncoupling of right ventricular function from the pulmonary circulation; bedside echocardiography of TAPSE/PASP adds to the prognostic relevance of $\mathrm{PaO}_{2} / \mathrm{FIO}_{2}$ in ARDS on COVID-19.

Keywords: COVID-19, ARDS, Right ventricular-arterial uncoupling, Echocardiography, Prognosis

\section{Background}

Severe Acute Respiratory Syndrome-CoronaVirus-2 (SARS-CoV-2) infection, or Corona Virus Infectious Disease 2019 (COVID-19), may be complicated by the acute respiratory distress syndrome (ARDS) with reported high mortality rates between 26 and 61\% [1,2]. There are data suggesting that COVID-19 respiratory failure differs from "typical" ARDS by several aspects, including preserved respiratory system compliance [3], good tolerance to hypoxemia ("happy hypoxemia") [4], and prominent micro- and macrovascular thrombotic changes in relation with extensive endothelial injury $[5,6]$. However, whether the respiratory physiology of COVID-19-induced ARDS really differs from other types of ARDS remains discussed [7]. On the cardiac side, COVID-19 has also been associated with myocardial injury [8] and altered right ventricle (RV) strain as an independent predictor of poor prognosis [9]. There are data suggesting that COVID-19 may predominantly affect the RV and that is clinically relevant [10].

Right heart failure ("acute cor pulmonale") is a longrecognized complication of ARDS, in relation to severity of the disease and ventilatory strategies associated with hyper-inflated lungs and permissive hypercapnia [11]. We hypothesized that myocardial injury and inflammatory changes in COVID-19 could be an additional cause of ARDS-related acute right heart failure. We therefore assessed the coupling of RV function to the pulmonary circulation in COVID-19 ARDS patients. To this purpose, we used bedside transthoracic echocardiography with focus on the tricuspid annular plane systolic excursion (TAPSE)/pulmonary artery systolic pressure (PASP) ratio, previously shown to be a valid surrogate of the gold standard ratio of end-systolic to arterial elastance (Ees/ Ea) for the assessment of RV-arterial coupling [12] and an independent predictor of outcome in heart failure and pulmonary arterial hypertension [13].

\section{Methods}

\section{Study design}

This was a prospective study from two Italian centres, Ospedale dei Colli (Monaldi-Cotugno) and Federico II Hospital, Naples, Italy, which are teaching hospitals authorized for COVID-19 patients. All patients were enrolled from 8 March to 8 May 2020. The diagnosis of COVID-19 was confirmed according to the interim guidance of World Health Organization [14]. The study was approved by local Ethics Committees (\#AOC/0015171/2020).

\section{Data collection}

Patients' demographics, clinical status, disease duration from the symptoms onset, medical history, comorbidities, laboratory examinations, concomitant treatment, type of ventilation, eventual complications, treatment, and outcomes were recorded. The diagnosis of ARDS rested on the Berlin consensus criteria and $\mathrm{PaO}_{2} / \mathrm{FIO}_{2}$ ratios discriminating mild, moderate, and severe forms of the disease [15]. Treatment was in keeping with current expert recommendations, with high-flow nasal $\mathrm{O}_{2}$ as needed to restore arterial oxygenation, and ventilation with positive end-expiratory pressure by facial mask or tracheal intubation following current expert recommendations [16]. Thus, tidal volume was kept as low as possible, on average to $6 \mathrm{ml} / \mathrm{kg}$; positive end-expiratory pressure titrated by $2-3 \mathrm{cmH}_{2} \mathrm{O}$ increments to a maximum of $10-15 \mathrm{cmH}_{2} \mathrm{O}$ and a plateau pressure $<30 \mathrm{cmH}_{2} \mathrm{O}$. Noninvasive ventilation was applied when endotracheal intubation was not considered necessary.

\section{Transthoracic echocardiography}

Bedside transthoracic echocardiographic examinations were performed with the Vivid E9 ultrasound system (General Electrics Medical Systems, Andover, MA, USA), according to the American Society of Echocardiography guidelines [17]. Images were stored and analyzed offline by three independent trained observers (MD, SS and AMM).

\section{Statistical analysis}

Kolmogorov-Smirnov test was applied to test the variable distribution. Normally distributed continuous variables were expressed as mean \pm standard deviation (SD); skewed distributed continuous data were expressed as median and interquartile range [IQR]; categorical variables were expressed as counts and percentages. Twotailed $t$ test for paired and unpaired data was used to assess changes between groups. Linear regression analyses and partial correlation test by Pearson's method were used to assess univariate relations. The association between analyzed variables and outcome (i.e., mortality) was established by using Cox proportional hazard 
regression analyses. Univariate and multivariable linear models were used to assess potential predictors of outcome. The following variables, selected according to their potential clinical relevance, were included in the analysis: age, sex, disease duration, previous lung disease, previous coronary artery disease, cardiovascular risk factors (hypertension, diabetes, obesity, smoke), therapy for COVID, type of ventilation, $\mathrm{PaO}_{2} / \mathrm{FiO}_{2}$ ratio, creatinine, cardiac troponin I, C-reactive protein, activated partial thromboplastin time, N-terminal pro-brain natriuretic peptide, interleukine-6, left ventricle (LV) end-diastolic diameter, LV end-systolic diameter, left atrium diameter, LV ejection fraction, mitral and aortic valve diseases, tricuspid regurgitation, TAPSE, PASP, TAPSE/ PASP ratio, inferior vena cava dimension and ratio of RV to LV surface areas on an apical 4-chamber view. Results were expressed as hazard ratios with $95 \%$ confidence intervals. Outcome prediction accuracies were tested by calculating the area under the curve (AUC) for the receiver operator characteristics (ROC) curve analysis for TAPSE/PASP and $\mathrm{PaO}_{2} / \mathrm{FiO}_{2}$ across the endpoint. Kaplan-Meier curves for cumulative survival were constructed for the endpoint to assess the impact of TAPSE/ PASP and $\mathrm{PaO}_{2} / \mathrm{FiO}_{2}$ on survival, categorizing patients using optimal cutoff points for TAPSE/PASP and $\mathrm{PaO}_{2} /$ $\mathrm{FiO}_{2}$ derived from Youden's Index from the ROC curve. Further, ROC curve analyses using the same multivariable model, with and without TAPSE/PASP and $\mathrm{PaO}_{2} /$ $\mathrm{FiO}_{2}$, were used to investigate the gain in C-statistic for associations with outcome when compared to the same model without these parameters. Statistical analyses were performed using SPSS version 25.0 (SPSS Inc, Chicago, Illinois, USA). A value of $p<0.05$ was considered statistically significant.

\section{Results}

Ninety-four patients were included in the study; they presented with fever $(94 / 94,100 \%)$, dyspnea (87/94, 93\%), fatigue $(94 / 94,100 \%)$ and cough $(58 / 94,62 \%)$. All patients had a computed tomography (CT) scan diagnostic for diffuse or localized pneumonia. The echocardiographic assessment was performed on average 3 days after hospital admission (range 1-7 days) after the patients had been stabilized with either high flow supplemental $\mathrm{O}_{2}$ or invasive/noninvasive ventilation.

The clinical data of the survivor and non-survivor patients are shown in Table 1.

The patient population was globally relatively old, predominantly male and presented with pulmonary comorbidities and cardiovascular risk factors. Nonsurvivors were older by an average of 6 years and were more frequently smokers and overweight. The majority of the patients were anticoagulated and treated with
Table 1 Comparison between alive and dead patients affected by COVID-19

\begin{tabular}{|c|c|c|c|}
\hline & Alive $(n=69)$ & Dead $(n=25)$ & $p$ \\
\hline Age (year) & $62 \pm 13$ & $68 \pm 12$ & 0.033 \\
\hline Sex M (\%) & $53(77)$ & $17(68)$ & 0.549 \\
\hline Disease duration (day) & $7.7 \pm 3.3$ & $7.7 \pm 3.1$ & 0.942 \\
\hline Lung disease (\%) & $17(25)$ & $11(44)$ & 0.079 \\
\hline Coronary artery disease (\%) & $14(20)$ & $3(12)$ & 0.545 \\
\hline \multicolumn{4}{|l|}{ Cardiovascular comorbidities } \\
\hline Hypertension (\%) & $44(64)$ & $19(76)$ & 0.362 \\
\hline Diabetes (\%) & $11(16)$ & $5(20)$ & 0.99 \\
\hline Smoke (\%) & $7(10)$ & $8(32)$ & 0.021 \\
\hline Obesity (\%) & $18(26)$ & $13(52)$ & 0.025 \\
\hline \multicolumn{4}{|l|}{ Treatment } \\
\hline Anticoagulants (\%) & $69(100)$ & $24(96)$ & 0.097 \\
\hline Hydroxycloroquine (\%) & $51(74)$ & $19(76)$ & 0.840 \\
\hline Antivirals (\%) & $43(62)$ & $23(92)$ & 0.005 \\
\hline Monoclonal antibodies (\%) & $8(12)$ & $10(40)$ & 0.005 \\
\hline Corticosteroids (\%) & $14(20)$ & $6(24)$ & 0.98 \\
\hline \multicolumn{4}{|l|}{ Type of ventilation } \\
\hline Nasal oxygen (\%) & $35(51)$ & $0(0)$ & $<0.001$ \\
\hline Noninvasive ventilation (\%) & $22(32)$ & $0(0)$ & $<0.001$ \\
\hline Intubation (\%) & $12(17)$ & $25(100)$ & $<0.032$ \\
\hline \multicolumn{4}{|l|}{ Biochemistry } \\
\hline Creatinine (mg/dl) & $1.3 \pm 1.3$ & $2.8 \pm 1.4$ & $<0.001$ \\
\hline Cardiac Troponin I (pg/l) & $365 \pm 644$ & $1245 \pm 2049$ & $<0.002$ \\
\hline D-dimer (ng/ml) & $317 \pm 557$ & $919 \pm 974$ & $<0.001$ \\
\hline C-reactive protein $(\mathrm{mg} / \mathrm{dl})$ & $10.6 \pm 19.9$ & $22.8 \pm 27.3$ & $<0.023$ \\
\hline Procalcitonin (ng/ml) & $0.6 \pm 1.5$ & $1.8 \pm 2.0$ & $<0.005$ \\
\hline APTT (sec) & $36.8 \pm 6.7$ & $40.6 \pm 4.3$ & 0.037 \\
\hline NT-proBNP (pg/ml) & $686 \pm 1224$ & $3375 \pm 3891$ & $<0.001$ \\
\hline Interleukine-6 (ng/ml) & $33.6 \pm 33.4$ & $246.4 \pm 87.4$ & $<0.001$ \\
\hline $\mathrm{PaO}_{2} / \mathrm{FiO}_{2}$ ratio $(\mathrm{mmHg})$ & $270 \pm 104$ & $117 \pm 56$ & $<0.001$ \\
\hline
\end{tabular}

Value are represented as mean \pm standard deviation or absolute value and (\%) APTT partial thromboplastin time, NT-proBNP N-terminal prohormone of brain natriuretic peptide, $\mathrm{PaO}_{2}$ arterial partial pressure of oxygen, $\mathrm{FiO}_{2}$ fraction of inspired $\mathrm{O}_{2}$

hydroxychloroquine. A proportion of the patients also received antiviral drugs, monoclonal antibodies, and corticosteroids. Non-survivors received more frequently antiviral drugs and invasive mechanical ventilation. Serum creatinine, cardiac troponin I, C-reactive protein, interleukine-6, $\mathrm{N}$-terminal pro-brain natriuretic peptide, activated partial thromboplastin time, and pro-calcitonin were higher and $\mathrm{PaO}_{2} / \mathrm{FIO}_{2}$ lower in non-survivors. An angio CT performed when dyspnea was deemed out of proportion of standard CT imaging revealed a pulmonary embolism in nine of the patients.

Echocardiographic findings shown in Table 2 disclosed a significant increase in PASP, inferior vena cava dimensions 
Table 2 Echocardiographic features

\begin{tabular}{|c|c|c|c|}
\hline & Alive $(n=69)$ & Dead $(n=25)$ & $p$ \\
\hline LVEDD (mm) & $48 \pm 5$ & $49 \pm 4$ & 0.388 \\
\hline LVESD (mm) & $29 \pm 7$ & $31 \pm 5$ & 0.059 \\
\hline LAD (mm) & $38 \pm 6$ & $40 \pm 5$ & 0.082 \\
\hline LVEF (\%) & $60 \pm 7$ & $58 \pm 8$ & 0.209 \\
\hline MVD & $5(7)$ & $1(4)$ & 0.574 \\
\hline AVD & $1(1)$ & $0(0)$ & 0.550 \\
\hline $\mathrm{TR}$ & $2(3)$ & $3(12)$ & 0.084 \\
\hline TAPSE (mm) & $25 \pm 4$ & $19 \pm 4$ & $<0.001$ \\
\hline PASP (mmHg) & $30 \pm 7$ & $42 \pm 12$ & $<0.001$ \\
\hline TAPSE/PASP & $0.89 \pm 0.29$ & $0.51 \pm 0.22$ & $<0.001$ \\
\hline IVC (mm) & $15 \pm 4$ & $20 \pm 3$ & $<0.001$ \\
\hline Pericardial effusion & $6(9)$ & $4(16)$ & 0.375 \\
\hline \multicolumn{4}{|c|}{ Echocardiographic phenotypes } \\
\hline Normal & $50(73)$ & $10(40)$ & 0.007 \\
\hline Hyperkinetic & $9(13)$ & $3(12)$ & 0.99 \\
\hline Right & $3(4)$ & $12(48)$ & $<0.001$ \\
\hline LV depression & $3(4)$ & $0(0)$ & 0.57 \\
\hline Severe pericardial effusion & $4(6)$ & $0(0)$ & 0.57 \\
\hline
\end{tabular}

Value are represented as mean \pm standard deviation or absolute value and (\%). $p<0.05$ statistically significant

$\angle V E D D$ left ventricle end-diastolic diameter, LVESD left ventricle end-systolic diameter, $L A D$ left atrium diameter, $L V E F$ left ventricle ejection fraction, $M V D$ mitral valve disease moderate-to-severe, AoVD aortic valve disease moderateto-severe, TR tricuspid regurgitation, TAPSE tricuspid annulus plane systolic excursion, $P A S P$ pulmonary artery systolic pressure, $I V C$ inferior vena cava

and a decrease in TAPSE/PASP in non-survivors, as compared to survivors.

A typical right heart phenotype echocardiographic examination is shown in Fig. 1 (Panel A and B).

The results of univariate and multivariable analyses are shown, respectively, in Table 3 and Table 4.

While at univariate analysis most of the biological and echocardiographic differences between survivors and non-survivors were significantly associated with survival (Table 3), only $\mathrm{PaO}_{2} / \mathrm{FIO}_{2}$ and TAPSE/PASP emerged as independent predictors after adjustment at multivariable analysis [hazard ratio ( $95 \%$ confidence interval); $\mathrm{p}$ value: 0.988 (0.977-0.998); $p=0.018$ and 0.026 (0.01-0.579); $p=0.019$, respectively] (Table 4).

Individual values for TAPSE/PASP and $\mathrm{PaO}_{2} / \mathrm{FIO}_{2}$ in survivors and non-survivors are presented in Fig. 2. ROC curves to predict outcome of these two variables are shown in Fig. 3. When patients were dichotomised according to the Youden's Index for optimal cutoff point from the ROC curve $\left(159 \mathrm{mmHg}\right.$ and $0.635 \mathrm{~mm} / \mathrm{mmHg}, \mathrm{PaO}_{2} / \mathrm{FIO}_{2}$ and TAPSE/PASP, respectively), Kaplan-Meyer curves of $\%$ survival as a function of time in patients showed that patients with TAPSE/PASP or $\mathrm{PaO}_{2} / \mathrm{FIO}_{2}$ below ROCderived cutoff values have reduced survival (chi square; log rank test $p: 26.43 ;<0.001$ and $42.83 ;<0.001$, respectively) (Fig. 4). Furthermore, when patients were categorized according to value of both parameters, patients with reduction of both parameters showed the lowest survival (chi square: 45.87 ; $\log$ rank test $p:<0.001)$, significantly different to those with normal levels (chi square: $50.32, p<0.001$ ) or only one parameter impaired (chi square: 9.56, $p=0.001$ ). A combination of high TAPSE/PASP or $\mathrm{PaO}_{2} / \mathrm{FIO}_{2}$ allowed for a very high likelihood of survival. Exclusion of the 9 pulmonary embolism patients from multivariate analysis did not affect the results.

\section{Discussion}

The present results show that COVID 19-induced ARDS is associated with early and pronounced uncoupling of right ventricular function from the pulmonary circulation and that its noninvasive echocardiographic assessment by the TAPSE/PASP ratio adds significantly and independently to the prognostic relevance of the $\mathrm{PaO}_{2} / \mathrm{FIO}_{2}$ ratio in these patients.

The reported COVID-19 patients were diagnosed with pneumonia complicated by ARDS based on clinical presentation of dyspnea, cough, and fatigue; compatible chest computed tomography findings; and the $\mathrm{PaO}_{2} / \mathrm{FIO}_{2}$ ratio. At the moment of echocardiographic evaluation, the $\mathrm{PaO}_{2} / \mathrm{FIO}_{2}$ ratio had been corrected in a proportion of the survivors (Fig. 2). The patients were treated empirically with drugs expected to be of benefit, such as hydroxychloroquine and were anticoagulated. Their ventilatory management included proning, application of positive endexpiratory pressure, and so-called "protective ventilation" with a low as possible tidal volumes [16]. This resulted in a $26 \%$ mortality at the lower range of currently reported [18].

Pulmonary hypertension in the present study was mild to moderate as based on echocardiographic estimates of PASP. A PASP of $40 \mathrm{mmHg}$ in the non-survivors would indeed be at the upper limit of normal taken into account age, sex, and body weight [19]. On the other hand, the TAPSE was decreased but still above the lower limit of normal in the non-survivors

(See figure on next page.)

Fig. 1 Coupling of right ventricular function to the pulmonary circulation evaluated by the tricuspid annular plane systolic excursion (TAPSE) to systolic pulmonary artery pressure (PASP) ratio. a Normal echocardiographic phenotype with increased pulmonary artery systolic pressure (PASP), normal tricuspid annulus plane systolic excursion (TAPSE), and preserved TAPSE/PASP. b Typical right heart echocardiographic phenotype with increased PASP, reduced TAPSE, low TAPSE/PASP, and right/left ventricular basal diameter ratio > 1. IVC inferior vena cava 


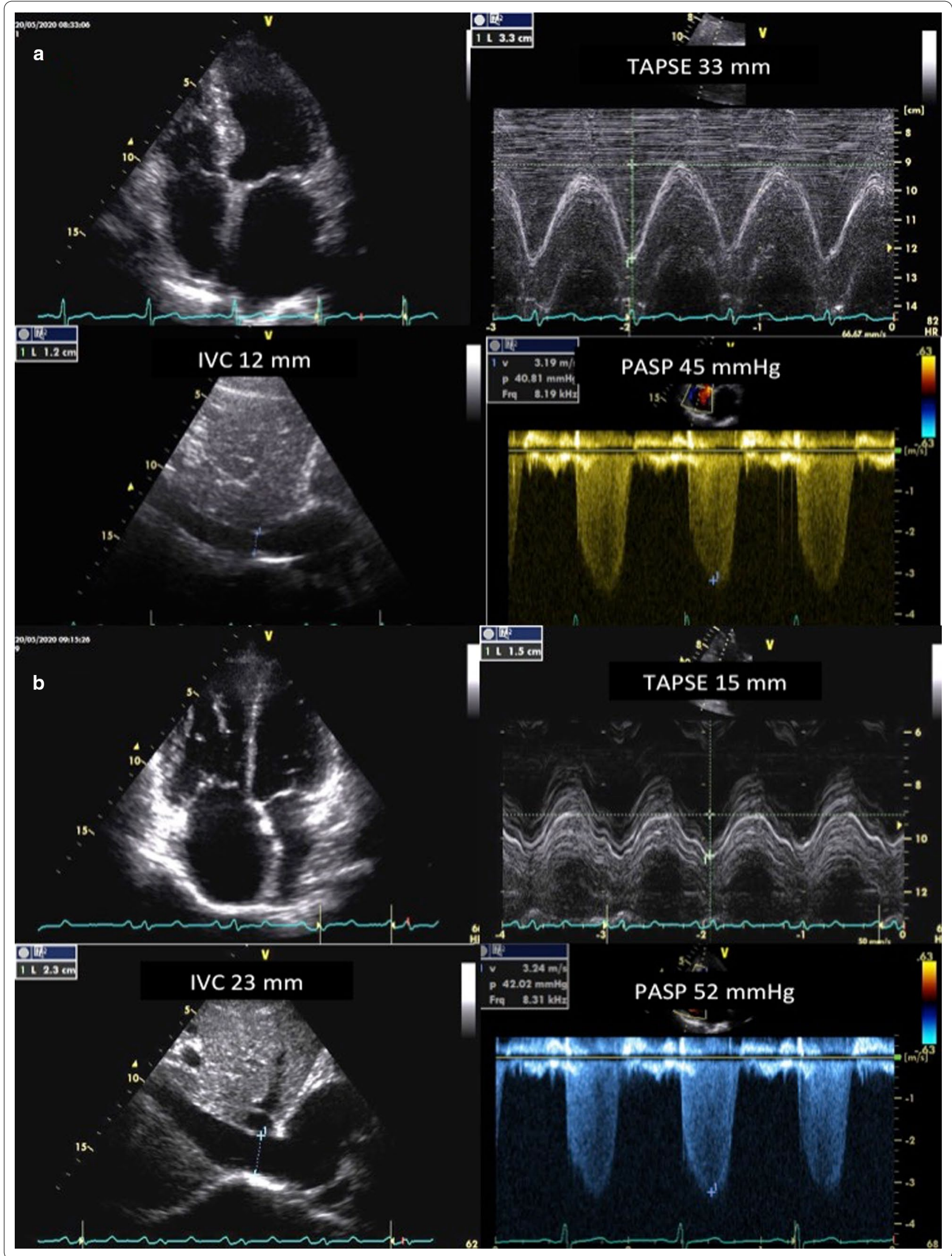


Table 3 Single predictor models of Cox proportional hazard analysis

\begin{tabular}{|c|c|c|c|}
\hline Variables & HR & $95 \%(\mathrm{Cl})$ & $p$ \\
\hline Age (year) & 1.04 & $1.003-1.078$ & 0.035 \\
\hline Sex (female) & 0.006 & $0.000-0.216$ & 0.006 \\
\hline Fever (days) & 1.001 & $0.912-1.098$ & 0.98 \\
\hline Pulmonary disease & 1.998 & $0.906-4.408$ & 0.086 \\
\hline Coronary artery disease & 0.556 & $0,166-1.858$ & 0.340 \\
\hline Hypertension & 1,767 & $0.706-4.429$ & 0.224 \\
\hline Diabetes & 1.525 & $0.571-4.072$ & 0.40 \\
\hline Smokers & 3.050 & $1.313-7.086$ & 0.10 \\
\hline Obesity & 2.252 & $1.027-4.936$ & 0.044 \\
\hline Risk factors & - & - & 0.025 \\
\hline 0 & Ref & - & - \\
\hline 1 & 6.608 & $0.853-51$ & 0.07 \\
\hline 2 & 5.126 & $0.617-42.6$ & 0.13 \\
\hline 3 & 15.518 & $1.861-129$ & 0.011 \\
\hline 4 & 46.105 & $2.772-766$ & 0.008 \\
\hline Nasal oxygen & 0.019 & $0.001-0.512$ & 0.018 \\
\hline Noninvasive ventilation & 0.031 & $0.001-1.386$ & 0.073 \\
\hline Intubation & 223,89 & $4.81-10,415$ & 0.006 \\
\hline $\mathrm{PaO}_{2} / \mathrm{FiO}_{2}$ ratio $(\mathrm{mmHg})$ & 0.986 & $0.981-0.992$ & 0.001 \\
\hline Heparin & 0.274 & $0.037-2.039$ & 0.206 \\
\hline Antivirals & 5.935 & $1.398-25.186$ & 0.016 \\
\hline Hydroxycloroquine & 1.195 & $0.477-2.995$ & 0.704 \\
\hline Monoclonal antibody & 3.301 & $1.481-7.356$ & 0.003 \\
\hline Corticosteroids & 1.308 & $0.521-3.279$ & 0.568 \\
\hline Creatinine (mg/mL) & 1.236 & $1.067-1.432$ & 0.005 \\
\hline Troponine (pg/l) & 1.000 & $1.000-1.000$ & 0.003 \\
\hline D-dimer (ng/ml) & 1.000 & $1.000-1.001$ & $<0.001$ \\
\hline C-reactive protein (mg/dl) & 1.014 & $1.004-1.024$ & 0.006 \\
\hline Procalcitonin (ng/ml) & 1.108 & $0.975-1.259$ & 0.115 \\
\hline NT-proBNP (pg/ml) & 1.000 & $1.000-1.000$ & $<0.001$ \\
\hline APTT (sec) & 0.997 & $0.982-1.012$ & 0.687 \\
\hline Interleukine-6 (ng/ml) & 1.010 & $1.007-1.013$ & $<0.001$ \\
\hline Heart rate (bpm) & 1.031 & $1.006-1.058$ & 0.016 \\
\hline Systolic blood pressure (mmHg) & 0.976 & $0.949-1.003$ & 0.076 \\
\hline Diastolic blood pressure $(\mathrm{mmHg})$ & 0.912 & $0.868-0.958$ & $<0.001$ \\
\hline LVEDd (mm) & 1.031 & $0.948-1.121$ & 0.473 \\
\hline LVESd (mm) & 1.039 & $0.99-1.091$ & 0.123 \\
\hline LAD (mm) & 1.066 & $0.995-1.143$ & 0.068 \\
\hline LVEF (\%) & 0.972 & $0.934-1.011$ & 0.151 \\
\hline Severe MR & 0.526 & $0.071-3.887$ & 0.529 \\
\hline Severe AR & 0.049 & $0-201,330$ & 0.697 \\
\hline Severe TR & 2.671 & $0.798-8.95$ & 0.111 \\
\hline TAPSE (mm) & 0.796 & $0.727-0.871$ & $<0.001$ \\
\hline $\mathrm{PASP}(\mathrm{mmHg})$ & 1.085 & $1.054-1.118$ & $<0.001$ \\
\hline TAPSE/PASP $(\mathrm{mm} / \mathrm{mmHg})$ & 0.013 & $0.002-0.069$ & $<0.001$ \\
\hline IVC (mm) & 1.335 & $1.201-1.483$ & $<0.001$ \\
\hline IVC respiratory changes & 1.591 & $0.702-3.606$ & 0.226 \\
\hline Pericardial effusion & 1.693 & $0.580-4.940$ & 0.335 \\
\hline Pleural effusion & 0.868 & $0.204-3.689$ & 0.848 \\
\hline
\end{tabular}

Table 3 (continued)

\begin{tabular}{|c|c|c|c|}
\hline Variables & HR & $95 \%(\mathrm{Cl})$ & $p$ \\
\hline Right phenotype & 4.232 & $1.505-11.902$ & 0.006 \\
\hline \multicolumn{4}{|c|}{$\begin{array}{l}\text { APTT partial thromboplastin time, NT-proBNP N-terminal prohormone of brain } \\
\text { natriuretic peptide, } L V E D D \text { left ventricle end-diastolic diameter, } L V E S D \text { left } \\
\text { ventricle end-systolic diameter, } L A D \text { left atrium diameter, } L V E F \text { left ventricle } \\
\text { ejection fraction, } M V D \text { mitral valve disease moderate-to-severe, AoVD aortic } \\
\text { valve disease moderate-to-severe, TR tricuspid regurgitation, TAPSE tricuspid } \\
\text { annulus plane systolic excursion, } P A S P \text { pulmonary artery systolic pressure, IVC } \\
\text { inferior vena cava }\end{array}$} \\
\hline
\end{tabular}

Table 4 Multivariable models of Cox proportional hazard analysis

\begin{tabular}{|c|c|c|c|}
\hline Variables & HR & $95 \%(\mathrm{Cl})$ & $p$ \\
\hline Age (year) & 1.002 & $0.944-1.063$ & 0.953 \\
\hline Obesity & 0.626 & $0.171-2.295$ & 0.480 \\
\hline Creatinine (mg/mL) & 1.033 & $0.746-1.429$ & 0.847 \\
\hline Troponine (pg/L) & 1.00 & $0.999-1.001$ & 0.774 \\
\hline D-dimer (ng/mL) & 1.00 & $0.999-1.001$ & 0.442 \\
\hline C-reactive protein (mg/mL) & 1.01 & $0.996-1.024$ & 0.171 \\
\hline Heart rate (bpm) & 0.996 & $0.961-1.032$ & 0.817 \\
\hline Systolic blood pressure (mmHg) & 1.038 & $0.988-1.09$ & 0.137 \\
\hline Diastolic blood pressure (mmHg) & 0.915 & $0.837-1.002$ & 0.054 \\
\hline LVEDd (mm) & 1.064 & $0.991-1.550$ & 0.508 \\
\hline LVESd (mm) & 0.899 & $0.707-1.143$ & 0.385 \\
\hline LVEF (\%) & 1.022 & $0.900-1.161$ & 0.739 \\
\hline LAD (mm) & 0.947 & $0.858-1.046$ & 0.947 \\
\hline TAPSE/PASP (mm/mmHg) & 0.026 & $0.01-0.579$ & 0.019 \\
\hline $\mathrm{PaO}_{2} / \mathrm{FiO}_{2}$ ratio $(\mathrm{mmHg})$ & 0.988 & $0.977-0.998$ & 0.018 \\
\hline
\end{tabular}

$\angle V E D D$ left ventricle end-diastolic diameter, $L V E S D$ left ventricle end-systolic diameter, $L V E F$ left ventricle ejection fraction, $L A D$ left atrium diameter, TAPSE tricuspid annulus plane systolic excursion, $P A S P$ pulmonary artery systolic pressure, $\mathrm{PaO}_{2}$ arterial partial pressure of oxygen, $\mathrm{FiO}_{2}$ fraction of inspired $\mathrm{O}_{2}$

[20]. Accordingly, the TAPSE/PASP at $0.89 \pm 0.29$ in survivors was mildly decreased compared to the value of $1.11 \pm 0.03$ previously reported in 209 subjects older than 60 years [20]. However, it was markedly decreased to $0.51 \pm 0.22 \mathrm{~mm} / \mathrm{mmHg}$ in non-survivors, approaching values below $0.50 \mathrm{~mm} / \mathrm{mmHg}$ previously shown to be of poor prognosis in heart failure and severe pulmonary hypertension [13].

In a recent report of 200 hospitalized with COVID-19 in non-ICU departments, PASP was $>35 \mathrm{mmHg}$ in $12 \%$ and the TAPSE $<17 \mathrm{~mm}$ in $14.5 \%$, but increased PASP and not decreased TAPSE was found to predict a poor outcome [21]. Mild pulmonary hypertensions along with moderate decrease in TAPSE in that study are in keeping with the present findings in more severely ill patients with respiratory insufficiency.

The TAPSE/PASP ratio was initially proposed as an estimate of RV myocardial length-tension relationship 

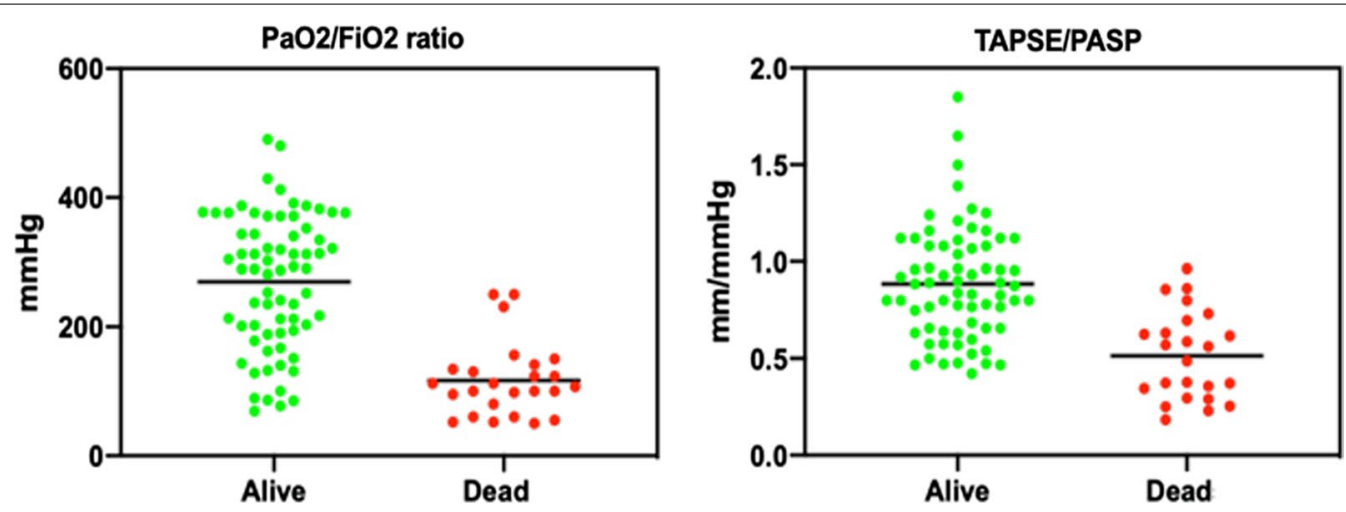

Fig. 2 Individual values for TAPSE/PASP and $\mathrm{PaO}_{2} / \mathrm{FIO}_{2}$ ratios. Individual values for the tricuspid annulus plane systolic excursion (TAPSE)/pulmonary artery systolic pressure (PASP) ratio (panel a), and arterial partial pressure of oxygen $\left(\mathrm{PaO}_{2}\right) /$ fraction of inspired $\mathrm{O}_{2}\left(\mathrm{FIO}_{2}\right)$ ratio (panel b). Means are indicated by horizontal bars. Both ratios were markedly decreased in non-survivors $(p<0.001)$

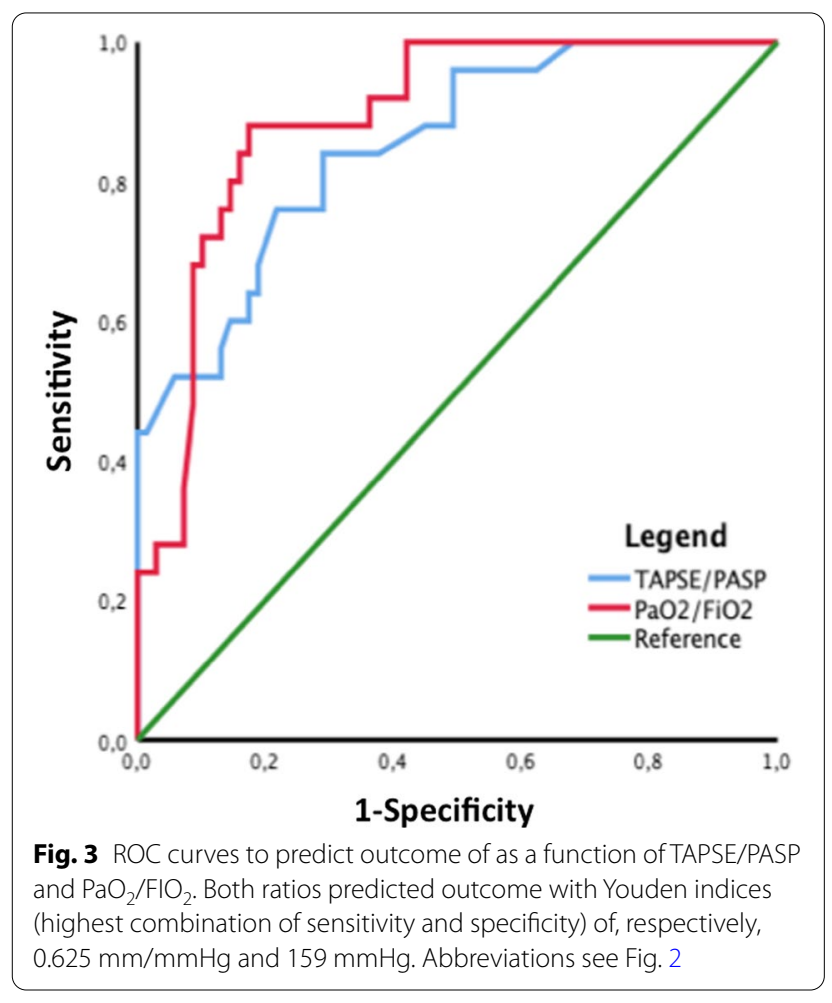

and as such showed to be of prognostic relevance in heart failure [21]. Subsequent studies confirmed its prognostic capability, not only in heart failure [22] but also in pulmonary arterial hypertension [23] and in patients with chronic lung diseases [24]. In these studies, the TAPSE/PASP was assumed to inform about RV-PA coupling, with TAPSE considered as a loaddependent surrogate of Ees and PASP as an indirect estimate of Ea [22-24]. The TAPSE/PASP has been shown to be superior to other composite echocardiographic indices in the assessment of RV-PA and correlated to gold standard invasive [12] or indirectly assessed Ees/Ea ratios [22].

As in the present study the TAPSE/PASP ratio was mostly decreased in invasively ventilated patients, one could wonder if the application of positive end-expiratory pressure could have contributed to increased PAP and RV-PA uncoupling [25]. COVID-19 ARDS patients could have presented with increased transmission of alveolar pressures to pulmonary resistive vessels because of preserved lung compliance [3]. Mechanics of the respiratory system were not assessed in the present study. However, the notion of preserved compliance in COVID-19 ARDS may not be confirmed in most of these patients $[7,26]$, and the "protective ventilation" approach in the present study would be expected to avoid to high volumes and alveolar pressures as a cause of excessive RV afterload [11]. This was confirmed by only mild increases in PASP disclosed by the echocardiographic examinations.

The reason for RV-PA uncoupling in the presence of only mildly increased PAP is not immediately apparent. The basic response of RV function to increased afterload is homeometric, with increased Ees (contractility) to match Ea (afterload), and uncoupling expected but only in severe or rapidly evolving pulmonary hypertension [27]. However, early RV-PA uncoupling may be observed in severe inflammatory conditions such as sepsis [28] or also in left heart failure because of negative ventricular interactions [29]. Both may occur in COVID-19 patients [8]. Therefore, the right heart in COVID-19 patients may fail even in the presence of only modest increase in afterload.

The present results are in keeping with a recent echocardiographic study in patients with COVID-19 ARDS, 

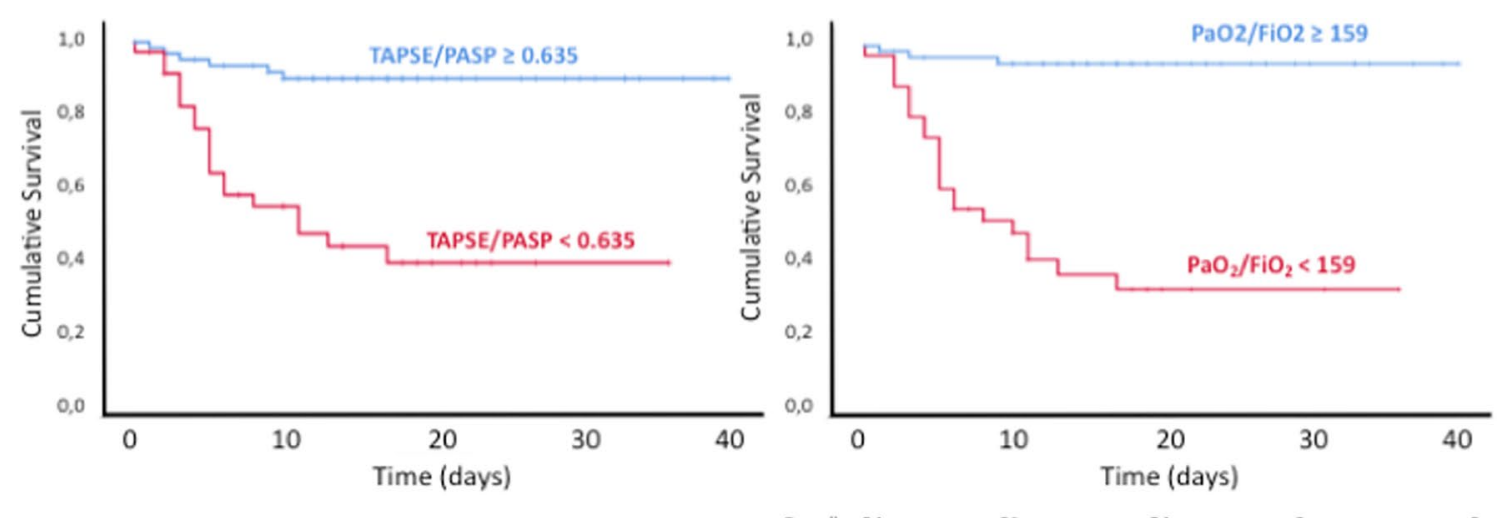

\begin{tabular}{|c|c|c|c|c|c|c|c|c|c|c|c|}
\hline Overall & 94 & 61 & 21 & 9 & 0 & Overall & 94 & 61 & 21 & 9 & 0 \\
\hline 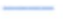 & 59 & 46 & 16 & 8 & 0 & & 59 & 49 & 18 & 7 & 0 \\
\hline & 35 & 15 & 5 & 1 & 0 & & 35 & 12 & 4 & 2 & 0 \\
\hline
\end{tabular}

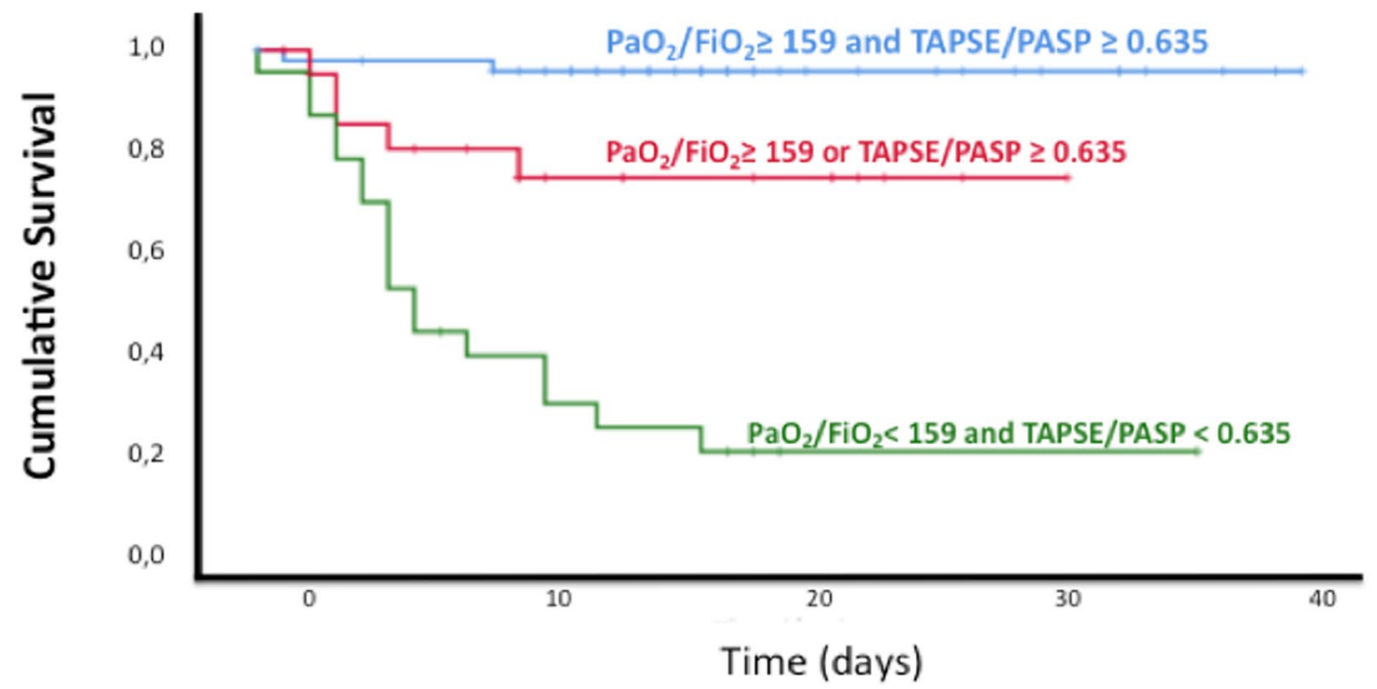

\begin{tabular}{|c|c|c|c|c|}
\hline Overall & 94 & 61 & 21 & 9 \\
\hline 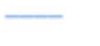 & 47 & 42 & 14 & 7 \\
\hline - & 23 & 11 & 6 & 1 \\
\hline- & 23 & 8 & 1 & 1 \\
\hline
\end{tabular}

Fig. 4 Survival according to TAPSE/PASP and $\mathrm{PaO}_{2} / \mathrm{FIO}_{2}$. Kaplan-Meyer curves of \% survival over time as a function of TAPSE/PASP and $\mathrm{PaO} / \mathrm{FIO} 2$ above or below the ROC-determined cutoff values of $0.625 \mathrm{~mm} / \mathrm{mmHg}$ and $159 \mathrm{mmHg}$, alone (upper panels) or in combination (lower panel). Abbreviations see Fig. 2

in which non-survivors had a PASP at the upper limit of normal, decreased indices of RV systolic function, and longitudinal strain identified as an independent predictor of outcome [9]. Pulmonary hypertension in
COVID-19 may belong either to pulmonary hypertension due to lung parenchymal disease or at most probably to chronic thromboembolic pulmonary hypertension. The TAPSE/PASP is easier to assess, can 
be part of standard bedside echocardiographic assessments as it does not require off-line analysis of images and specific software, and may be a more sensitive assessment of RV-PA coupling. The high prevalence of RV dilatation and dysfunction in the range of $40-50 \%$ recently reported in patients with COVID-19 [10, 30] underscore the exquisite sensitivity of the RV to this newly appeared viral infection.

The most potent predictor of outcome in ARDS is the $\mathrm{PaO}_{2} / \mathrm{FIO}_{2}$ ratio, which as such is part of the definition of the syndrome [14]. In the present study, the TAPSE/ PASP emerged with equally potent prognostic capability, suggesting a major component of acute cor pulmonale in COVID-19 ARDS pathophysiology. Whether this is entirely particular to COVID-19 ARDS is uncertain as there have been no systematic evaluations of RV-PA coupling in more "typical" ARDS or other viral pneumonia ARDS controls.

The present study is limited by relatively small sample size and by the small number of events. This might limit the results of the multivariate analyses and lead to a certain over-fitting. An angio-CT to diagnose acute pulmonary embolism was performed on physician in care's clinical suspicion, so that the frequency of this complication might have been under-estimated. However, PAP in the present study in the present study remained at the upper limit of normal, excluding pulmonary embolism as a cause of afterload-induced RV-PA uncoupling. Furthermore, excluding 9 of the patients with a diagnosis of pulmonary embolism did not affect the predictive capability of the TAPSE/ PASP and $\mathrm{PaO}_{2} / \mathrm{FIO}_{2}$ ratios. Other limitations might be absence of respiratory system compliance measurements, absence of non-COVID-19 viral pneumonia controls, and exclusively noninvasive evaluations of the right heart and the pulmonary circulation. However, the results call attention to cor pulmonale as an important component of COVID-19 ARDS and plea for systematic bedside echocardiographic assessments added to blood gases and lung mechanics in the management of these patients.

Approximately 4 decades ago, Zapol and Snider called attention to the pulmonary circulation and the right heart in severe ARDS [31]. Pulmonary hypertension in these patients is nowadays uncommon along with progress in management, but "acute cor pulmonale" continues to be reported, albeit generally in the context of ventilatory settings associated with excessive increase in alveolar pressure and permissive hypercapnia [11]. The present investigation shows that acute uncoupling of the right heart from the quasi-normotensive pulmonary circulation may also occur in the context of severe systemic inflammation and vasculitis.

\section{Conclusions}

In conclusion, COVID 19-induced ARDS is associated with early and pronounced right ventricular-arterial uncoupling, and its noninvasive echocardiographic assessment by the TAPSE/PASP ratio adds significantly and independently to the prognostic relevance of the $\mathrm{PaO}_{2} / \mathrm{FIO}_{2}$ ratio in these patients. These data call for the indispensable integration of bedside echocardiography in the assessment of COVID-19 patients in the intensive care setting.

\section{Abbreviations \\ ARF: Acute respiratory failure; ARDS: Acute respiratory distress syndrome; AUC : Area under the curve; COVID-19: Corona Virus Infectious Disease 2019; CT: Computed tomography; Ea: Arterial elastance; Ees: End-systolic elastance; $\mathrm{FIO}_{2}$ Fraction of inspired $\mathrm{O}_{2}$; IQR: Interquartile range; $\mathrm{LV}$ : Left ventricle; $\mathrm{PaO}_{2}$ : Arterial partial pressure of oxygen; PASP: Systolic pulmonary artery pressure; ROC: Receiver operator characteristics; RV: Right ventricle; SARS-CoV-2: Severe acute respiratory syndrome-coronavirus-2; SD: Standard deviation; TAPSE: Tricuspid annular plane systolic excursion.}

\section{Acknowledgements}

We thank all study participants and staff from Monaldi Hospital, Cotugno Hospital and Federico II University Hospital.

\section{Authors' contributors}

$M D$ and $A M M$ had full access to all of the data in the study and take responsibility for the integrity of the data and the accuracy of the data analysis, including especially any adverse effects. MD, AMM, AS, PG, and RN contributed to the study design, data analysis, and interpretation. SS, ER, RDR, FMS, GP, RV, PM, $A F, G C, M V, G F, S G, I G, A C$, and $A C$ contributed to data analysis and interpretation. $M D, A M, R N$, and $P G$ contributed to writing of the manuscript. MD, AM, $\mathrm{RN}$, and PG contributed to critically revising of the manuscript. All authors read and approved the final manuscript.

\section{Funding}

This research did not receive any specific grant from funding agencies in the public, commercial, or not-for-profit sectors.

\section{Availability of data and materials}

The data set used for this manuscript will be available from the corresponding author upon reasonable request.

\section{Ethics approval and consent to participate}

This study was approved by the Institutional Ethics Committees of Monaldi Hospital (\#AOC/0015171/2020). All data were anonymized to comply with the provisions of personal data protection legislation. Due to the retrospective nature of this study and due the fact that only historical medical data were collected, written informed consent was not required.

\section{Consent for publication}

Not applicable.

\section{Competing interests}

The authors declare that they have no competing interests.
Author details
${ }^{1}$ Department of Cardiology, Monaldi Hospital - "L. Vanvitelli" University, Naples, Italy. ${ }^{2}$ Department of Translational Medical Sciences, "Federico II" University, Naples, Italy. ${ }^{3}$ Department of Cardiology, Cotugno Hospital, Naples, Italy. ${ }^{4}$ IRCCS SDN, Diagnostic and Nuclear Research Institute, Naples, Italy. ${ }^{5}$ Department of Anesthesiology, Monaldi Hospital, Naples, Italy. ${ }^{6}$ Depart- ment of Neurosciences, Reproductive and Odontostomatological Sciences, "Federico II" University Hospital and School of Medicine, Naples, Italy. ${ }^{7}$ Depart- ment of Intensive Care, Monaldi Hospital, Naples, Italy. ${ }^{8}$ Department of Clinical Medicine and Surgery, Section of Infectious Diseases, "Federico II" University 
Hospital and School of Medicine, Naples, Italy. ${ }^{9}$ Department of Pathophysiology, Free University of Brussels, Brussels, Belgium.

Received: 9 September 2020 Accepted: 12 November 2020

Published online: 30 November 2020

\section{References}

1. Grasselli G, Zangrillo A, Zanella A, Antonelli M, Cabrini L, Castelli A, Cereda D, Coluccello A, Foti G, Fumagalli R, lotti G, Latronico N, Lorini L, Merler S, Natalini G, Piatti A, Ranieri MV, Scandroglio AM, Storti E, Cecconi M, Pesenti M. COVID-19 lombardy ICU network. Baseline characteristics and outcomes of 1591 patients infected with SARS-CoV-2 admitted to ICUs of the Lombardy region, Italy. JAMA. 2020;323:1574-81.

2. Bhatraju PK, Ghassemieh BJ, Nichols M, Kim R, Jerome KR, Nalla AK, Greninger AL, Pipavath S, Wurfel MM, Evans L, Kritek PA, West TE, Luks A, Gerbino A, Dale CR, Goldman JD, O'Mahony S, Mikacenic C. Covid-19 in critically III patients in the Seattle region—case series. N Engl J Med. 2020;382:2012-22.

3. Gattinoni L, Coppola S, Cressoni M, Busana M, Chiumello D, Rossi S. COVID-19 does not lead to a "typical" acute respiratory distress syndrome. Am J Respir Crit Care Med. 2020;201:1299-300.

4. Ottestad W, Søvik S. COVID-19 patients with respiratory failure: what can we learn from aviation medicine? Brit J Anaesth 2020;S0007-0912:(20)30226-9.

5. Klok FA, Kruip MJHA, Meer NJM, van der, Arbous MS, Gommers D, Kant KM, Kaptein FHJ, van Paassen J, Stals MAM, Huisman MV, Endeman H. Incidence of thrombotic complications in critically ill ICU patients with COVID-19. Thromb Res 2020;50049-3848:(20)30120-1.

6. Huertas A, Montani D, Savale L, et al. Endothelial cell dysfunction: a major player in SARS-CoV-2 infection (COVID-19)?. Eur Respir J. 2020;56(1):2001634. https://doi.org/10.1183/13993003.01634-2020.

7. Grieco DL, Bongiovanni F, Chen L, Menga LS, Cutuli SL, Pintaudi G, Carelli S, Michi T, Torrini F, Lombardi G, Anzellotti GM, De Pascale G, Urbani A, Bocci MG, Tanzarella ES, Bello G, Dell'Anna AM, Maggiore SM, Brochard L, Antonelli M. Respiratory physiology of COVID-19-induced respiratory failure compared to ARDS of other etiologies. Crit Care. 2020;24(1):529. https://doi.org/10.1186/s13054-020-03253-2.

8. Santoso A, Pranata R, Wibowo A, Wibowo A, Al-Farabi MJ, Huang I, Antariksa B. Cardiac injury is associated with mortality and critically ill pneumonia in COVID-19: A meta-analysis. Am J Emerg Med. 2020;50735-6757:(20)30280-1.

9. Li Y, Li H, Zhu S. Prognostic value of right ventricular longitudinal strain in patients with COVID-19. JACC Cardiovasc Imaging 2020 [E-pub ahead of print]. https://doi.org/10.1016/j.jcmg.2020.04.014.

10. Szekely Y, Lichter Y, Taieb P, Banai A, Hochstadt A, Merdler I, Gal Oz A, Rothschild E, Baruch G, Peri Y, Arbel Y, Topilsky Y. Spectrum of cardiac manifestations in COVID-19: a systematic echocardiographic study. Circulation. 2020;142:342-53.

11. Vieillard-Baron A, Price LC, Matthay MA. Acute cor pulmonale in ARDS. Intens Care Med. 2013;39:1836-8.

12. Tello K, Wan J, Dalmer A, Vanderpool R, Ghofrani HA, Naeije R, Roller F, Mohajerani E, Seeger W, Herberg U, Sommer N, Gall H, Richter MJ. Validation of the tricuspid annular plane systolic excursion/systolic pulmonary artery pressure ratio for the assessment of right ventricular-arterial coupling in severe pulmonary hypertension. Circ Cardiovasc Imaging. 2019;12(9):e009047.

13. Guazzi M. Use of TAPSE/PASP ratio in pulmonary arterial hypertension: an easy shortcut in a congested road. Int J Cardiol. 2018;266:242-4.

14. World Health Organization. Clinical management of severe acute respiratory infection when novel coronavirus ( $\mathrm{nCoV}$ ) infection is suspected. Published March 13, 2020.

15. Ranieri VM, Rubenfeld GD, Thompson B, Ferguson ND, Caldwell E, Fan E, Camporota L, Slutsky AS. Acute respiratory distress syndrome: the Berlin definition. JAMA. 2012;307:2526-33.
16. Matthay MA, Aldrich JM, Gotts JE. Treatment for severe acute respiratory distress syndrome from COVID-19. Lancet Respir Med. 2020;8:433-4.

17. Lang RM, Badano LP, Mor-Avi V, Afilalo J, Armstrong A, Ernande L, Flachskampf FA, Foster E, Goldstein SA, Kuznetsova T, Lancellotti P, Muraru D, Picard MH, Rietzschel ER, Rudski L, Spencer KT, Tsang W, Voigt JU. Recommendations for cardiac chamber quantification by echocardiography in adults: an update from the American Society of Echocardiography and the European Association of Cardiovascular Imaging. J Am Soc Echocardiogr. 2015;28:1-39.

18. Wunsch H. Mechanical ventilation in COVID-19. Interpreting the current epidemiology. Am J Respir Crit Care Med 2020; 202:1-4.

19. McQuillan BM, Picard MH, Levitt M, Weyman AE. Clinical correlates and reference intervals for pulmonary artery systolic pressure among echocardiographically normal subject. Circulation. 2001;104:2797-802.

20. Ferrara F, Rudski LG, Vriz O, Gargani L, Afilalo J, D'Andrea A, D'Alto M, Marra AM, Acri E, Stanziola AA, Ghio S, Cittadini A, Naeije R, Bossone E. Physiologic correlates of tricuspid annular plane systolic excursion in 1168 healthy subjects. Int J Cardiol. 2016;223:736-43.

21. Guazzi M, Bandera F, Pelissero G, Castelvecchio S, Menicanti L, Ghio S, Temporelli PL, Arena R. Tricuspid annular plane systolic excursion and pulmonary arterial systolic pressure relationship in heart failure: an index of right ventricular contractile function and prognosis. Am J Physiol Heart Circ Physiol. 2013;305:H1373-1381.

22. Guazzi M, Dixon D, Labate V, Beussink-Nelson L, Bandera F, Cuttica MJ, Shah SJ. RV contractile function and its coupling to pulmonary circulation in heart failure with preserved ejection fraction: stratification of clinical Phenotypes and outcomes. JACC Cardiovasc Imaging. 2017;10:1211-21.

23. Tello K, Axmann J, Ghofrani HA, Naeije R, Narcin N, Rieth A, Seeger W, Gall $\mathrm{H}$, Richter MJ. Relevance of the TAPSE/PASP ratio in pulmonary arterial hypertension. Int J Cardiol. 2018;266:229-35.

24. Tello K, Ghofrani HA, Heinze C, Krueger K, Naeije R, Raubach C, Seeger W, Sommer N, Gall H, Richter MJ. A simple echocardiographic estimate of right ventricular-arterial coupling to assess severity and outcome in pulmonary hypertension on chronic lung disease. Eur Respir J. 2019:54(3):1802435.

25. Vieillard-Baron A, Prin S, Chergui K, Dubourg O, Jardin F. Echo-Doppler demonstration of acute cor pulmonale at the bedside in the medical intensive care unit. Am J Respir Crit Care Med. 2002;166:1310-9.

26. Ziehr DR, Alladina J, Petri CR, Maley JH, Moskowitz A, Medoff BD, Hibbert KA, Thompson BT, Hardin CC. Respiratory pathophysiology of mechanically ventilated patients with COVID-19: a cohort study. Am J Respir Crit Care Med. 2020;201:1560-4.

27. Sanz J, Sánchez-Quintana D, Bossone E, Bogaard HJ, Naeije R. Anatomy, function, and dysfunction of the right ventricle: JACC state-of-the-art review. J Am Coll Cardiol. 2019;73:1463-82.

28. Lambermont $B$, Ghuysen $A$, Kolh $P$, Tchana-Sato V, Segers $P$, Gérard $P$, Morimont $P$, Magis D, Dogné JM, Masereel B, D'Orio V. Effects of endotoxic shock on right ventricular systolic function and mechanical efficiency. Cardiovasc Res. 2003;59:412-8.

29. Pagnamenta A, Dewachter C, McEntee K, Fesler P, Brimioulle S, Naeije R. Early right ventriculo-arterial uncoupling in borderline pulmonary hypertension on experimental heart failure. J Appl Physiol. 2010;109:1080-5.

30. Mahmoud-Elsayed HM, Moody WE, Bradlow WM, Khan-Kheil AM, Senior J, Hudsmith LE, Steeds RP. Echocardiographic findings in patients with COVID-19 pneumonia. Can J Cardiol. 2020;36:1203-7.

31. Zapol WM, Snider MT. Pulmonary hypertension in acute severe respiratory failure. N Engl J Med. 1977;296:476-80.

\section{Publisher's Note}

Springer Nature remains neutral with regard to jurisdictional claims in published maps and institutional affiliations. 